\title{
Impact of Chorioamnionitis on Exhaled Nitric Oxide and Endotracheal Aspirate Levels of Nitrites-Nitrates and Interleukin-8 in Mechanically Ventilated Preterm Neonates
}

\author{
Josep Figueras-Aloy, MD, PhD, ${ }^{1 *}$ Maria Dolors Salvia-Roiges, $\mathrm{MD}, \mathrm{PhD},{ }^{1}$ \\ J. Manuel Rodriguez-Miguélez, MD, PhD, ${ }^{1}$ Xavier Miracle-Echegoyen, ${ }^{1},{ }^{1}$ \\ Francesc Botet-Mussons, MD, PhD, ${ }^{1} \mathrm{~J}$. Luís Marín-Soria, $\mathrm{MD}^{2}{ }^{2}$ and \\ Xavier Carbonell-Estrany, $\mathrm{MD}, \mathrm{PhD}^{1}$
}

\begin{abstract}
Summary. Objectives: To assess the influence of maternal chorioamnionitis on early exhaled nitric oxide (NO) and levels of nitrites-nitrates and interleukin (IL)-8 in endotracheal aspirate fluid in mechanically ventilated preterm neonates. Study Design: Cross-sectional study. Patient-Subject Selection: Between September 2007 and August 2009, 54 mechanically ventilated preterm neonates were included. Patients were divided into two groups according to the presence or absence of maternal chorioamnionitis, and those without chorioamnionitis (controls) were further stratified into two subgroups by birth weight $<$ or $\geq 2,000 \mathrm{~g}$. Methodology: The ventilator used was a Babylog 8000 . The NO level assessed was the plateau value given by the software of the Sievers NOA apparatus. Collection of endotracheal aspirate fluid samples was performed coinciding with routine aspirations and using the dry technique. Results: The two groups of control neonates showed statistically significant differences in exhaled NO expressed as $\mathrm{nl} / \mathrm{min}$ and normalized exhaled NO expressed as either $\mathrm{nl} / \mathrm{min}$ or $\mathrm{nl} / \mathrm{min} / \mathrm{kg}$, so they are not homogeneous and cannot be used in clinical practice. Serum C-reactive protein and endotracheal aspirate levels of nitritesnitrates were significantly higher in the chorioamnionitis group than in controls ( $3.6 \mathrm{vs} .1 .07 \mu \mathrm{mol} / \mathrm{L}$; $P=0.035)$. Nitrites-nitrates levels were positively correlated with exhaled NO in ppb $(\rho=0.367$; $P=0.006)$. Minute exhaled endogenous NO was significantly higher in the chorioamnionitis group ( 0.48 vs. $0.27 \mathrm{nl} / \mathrm{min} / \mathrm{kg} ; P=0.021)$. Conclusions: In mechanically ventilated preterm infants weighing $<2,000 \mathrm{~g}$, maternal chorioamnionitis was associated with an increase of early exhaled $\mathrm{NO}(\mathrm{nl} / \mathrm{min} / \mathrm{kg})$ and serum levels of C-reactive protein and levels of nitrites-nitrates in endotracheal aspirate fluid. Pediatr Pulmonol. 2011; 46:595-603. ๑ 2011 Wiley-Liss, Inc.
\end{abstract}

Key words: chorioamnionitis; exhaled nitric oxide; newborn; preterm; nitrites-nitrates; interleuchin-8.

Funding source: National Health Service, Number: FISS PI060052, Instituto Carlos III, Madrid, Spain.

\section{INTRODUCTION}

Maternal chorioamnionitis may cause preterm delivery and be associated with an adverse perinatal outcome, including early-onset sepsis, necrotizing enterocolitis, and lung disease as well as long-term sequelae in the infant. ${ }^{1-4}$ Histologic chorioamnionitis is associated with an increased incidence of bronchopulmonary dysplasia (BPD) ${ }^{5}$ a chronic lung disease that prolongs hospital stay and causes greater morbidity and mortality of respiratory origin. ${ }^{6-9}$

Chorioamnionitis may injure the fetal lung through the activation of alveolar neutrophils and macrophages. Due to this activation, greater expression of inducible nitric oxide (NO) synthase is to be expected, with elevation of nitrites and nitrates in endotracheal aspirates and of
${ }^{1}$ Institut Clínic de Ginecologia, Obstetrícia i Neonatologia, Hospital Clínic, IDIBAPS (Institut d'Investigacions Biomèdiques August Pi i Sunyer), Universitat de Barcelona, Barcelona, Spain.

${ }^{2}$ Centre de Diagnòstic Biomèdic, Hospital Clínic, Universitat de Barcelona, Barcelona, Spain.

The authors declare that they have no competing interests.

*Correspondence to: Prof. Josep Figueras-Aloy, MD,PhD, Servicio Neonatología, Hospital Clínic (sede Maternitat), C/Sabino de Arana 1, 08028 Barcelona, Spain. E-mail: jfiguer@clinic.ub.es

Received 16 June 2010; Revised 3 December 2010; Accepted 5 December 2010.

DOI 10.1002/ppul.21410

Published online 18 January 2011 in Wiley Online Library

(wileyonlinelibrary.com). 
minute exhaled NO. Exhaled NO is raised in adults and children with asthma, ${ }^{10,11}$ and has also been detected among the gases exhaled in mechanically ventilated neonates. ${ }^{12-17}$ Different results of exhaled NO in neonates with BPD have been reported, including lower values in infants breathing spontaneously ${ }^{18}$ and higher exhaled NO peak levels in ventilated infants. ${ }^{19}$ Differences in postnatal age ${ }^{16-19}$ and in the methods for assessing exhaled NO (breathing spontaneously or on assisted ventilation, ${ }^{6,18}$ output or minute ventilation obtained using plateau NO values, ${ }^{18}$ or peak or maximum values of exhaled $\mathrm{NO}^{19}$ ) may account for the conflicting results. Although recommendations concerning standardized techniques for measurement of exhaled NO have been reported, ${ }^{20}$ data for analysis of exhaled NO in mechanically ventilated preterm infants are lacking. Williams et al. ${ }^{21}$ studied the influence of ventilatory settings on measurements of exhaled NO and found that increasing peak inflating pressure as well as the inspired oxygen concentration resulted in a decrease in the peak NO levels. The authors emphasized that the conditions of measurement must be standardized in infants receiving respiratory support. In a previous study of our group, ${ }^{22}$ the following points were suggested when collecting gas samples from ventilated premature infants to obtain exhaled NO: (1) it would suffice to collect exhaled gas during $1 \mathrm{~min}$, although it is recommended to repeat collection three times; ${ }^{15}$ (2) for each sample collection, the parameters to record should be fraction of inspiratory oxygen $\left(\mathrm{FiO}_{2}\right)$, peak inspiratory pressure (PIP), positive end expiratory pressure (PEEP), respiratory frequency (RF), I/E, volume/ minute, and percentage of leakage (the two latter ones, every $15 \mathrm{sec}$ during collection); and (3) the results should be expressed as exhaled NO (ppb plateau value), "minute exhaled NO/kg after correction for leakage" (exhaled $\mathrm{NO} \times$ volume $/ \mathrm{min} /$ weight in $\mathrm{kg}=\mathrm{nl}$ or $\mathrm{ppb} / \mathrm{min} / \mathrm{kg}$ ) and "normalized minute exhaled $\mathrm{NO} / \mathrm{kg}$ after correction for leakage" (after applying the normalization equation). ${ }^{22}$

The cellular composition of tracheal aspirate is the gold standard for defining lung inflammation. ${ }^{23}$ Interleukin-8 (IL-8) is produced by alveolar macrophages, fibroblasts, type II pneumocytes, and endothelial cells. Hypoxia, hyperoxia, and endotoxins stimulate the synthesis of IL-8, which is a major neutrophil chemotactic factor in the lung. Histologic chorioamnionitis is associated with an increase of IL-8 in endotracheal aspirate fluid along the first day of life $(\geq 917 \mathrm{pg} / \mathrm{ml})$ and this cutpoint may be used for diagnosis. ${ }^{24}$ Preterm infants suffering from BPD can present increased levels of tumor necrosis alpha (TNF-alfa), ${ }^{25} \mathrm{IL}-6,{ }^{25} \mathrm{IL}-8,{ }^{26}$ and IL- $10^{26}$ in endotracheal aspirates.

The present study was designed to assess changes of early exhaled NO and the concentration of nitrites-nitrates and IL-8 in endotracheal aspirate fluid in mechanically ventilated preterm neonates with and without history of maternal chorioamnionitis.

\section{MATERIALS AND METHODS}

\section{Design and Patient Population}

A cross-sectional study of mechanically ventilated preterm infants was conducted to assess the impact of chorioamnionitis on exhaled $\mathrm{NO}$ and the concentration of nitrites-nitrates and IL-8 in endotracheal aspirates. Between September 2007 and August 2009, 54 mechanically ventilated preterm neonates treated in the Neonatology Service of a IIIB level neonatal intensive care unit were eligible. Inclusion criteria were gestational age between 25 weeks 0 days and 36 weeks 6 days, $<36 \mathrm{hr}$ of age, presence of mechanical ventilation for the treatment of respiratory distress syndrome (RDS), hemodynamic stability, and written informed consent obtained from the parents or legal guardians. Newborns with pulmonary hypoplasia or other respiratory conditions other than RDS, major congenital malformations, chromosomal abnormalities, sepsis, or treatment with NO donor drugs were excluded. Patients were divided into two groups according to the presence or absence of maternal chorioamnionitis, and those without history of chorioamnionitis (controls) were further stratified into two subgroups according to birth weight $<2,000 \mathrm{~g}$ or $\geq 2,000 \mathrm{~g}$. The study protocol was approved by the Ethics Committee of Hospital Clinic of Barcelona, Spain. The parents or legal guardians were informed about the study and provided consent because no blood sampling was needed and procedures performed were not painful and were included in the care of the patients (tracheal aspirates).

\section{Definitions and Procedures}

The diagnosis of clinical chorioamnionitis in the pregnant woman who presented with premature labor or premature rupture of the membranes was made in the presence of some combination of uterine pain, fever $\left(\geq 38^{\circ} \mathrm{C}\right)$, leukocytosis $\left(>12,000\right.$ cells $\left./ \mathrm{mm}^{3}\right)$, and increased serum concentrations of C-reactive protein $(>30 \mathrm{mg} / \mathrm{L})$ without any clear focus of infection. In these cases, amniotic fluid and placenta were microbiologically cultured, and placenta and umbilical cord histologically analyzed. Chorioamnionitis was diagnosed when clinical data were accompanied by a positive culture from amniotic fluid and placenta (fetal and maternal sites) and histological findings of chorioamnionitis. Polymorphonuclear infiltration in the placenta and umbilical cord was required to establish a diagnosis of histological chorioamnionitis. Mild chorioamnionitis had a few neutrophils (5-10 neutrophils per high-power field) scattered in the subchorionic space and adjacent chorion; moderate chorioamnionitis had many neutrophils (11-30 neutrophils per high-power 
field) in the lower half of the chorionic plate and the subchorionic space; and severe chorioamnionitis had dense infiltrates of neutrophils (30 per high-power field) throughout the chorionic plate into the amnion. Mild chorioamnionitis was recorded in seven cases, moderate in three, and severe in five.

RDS was defined in the presence of a typical clinical course and chest radiographic findings, with clinical improvement when exogenous surfactant was administered. RDS was considered non-severe if only one dose of exogenous surfactant was needed and severe if two or more doses of exogenous surfactant or high-frequency oscillatory ventilation were needed as well as in the presence of air leak or if RDS was the cause of death. BPD was defined according to diagnostic criteria of Jobe and Bancalari. ${ }^{27}$

At all times, neonates received appropriate medical care according to his/her clinical condition. Special attention was placed to maintain the inspired gas temperature at $37^{\circ} \mathrm{C}$ and maximum humidity of the circuit (100\%) using a Fisher-Paykel humidifier. Serial measurements of heart rate, RF, non-invasive blood pressure, and arterial blood gases were performed. Ventilatory parameters included PIP, PEEP, inspiratory time (Ti), effective RF, tidal volume $(\mathrm{Vt})$, minute volume $(\mathrm{Vm})$, and compliance (A). The Clinical Risk Index for Babies (CRIB) score (in infants weighing $<1,500 \mathrm{~g}$ ) and the Score for Neonatal Acute Physiology (SNAP) and SNAP Perinatal Extension (SNAPPE II) score were assessed to check homogeneity of the patients' severity of illness.

All infants were mechanically ventilated using a constant flow, time cycled, pressure-limited device (Babylog 8000 Plus, Dräger Medical AG \& Co. KGaA, Lübeck, Germany), which measures all ventilatory parameters displayed in the screen of the device during the expiratory time. Oxygenation was continuously monitored by pulse oximetry to maintain arterial blood oxygen saturation $\left(\mathrm{SaO}_{2}\right)$ between $88 \%$ and $93 \%$ and arterial partial pressure $\left(\mathrm{PaO}_{2}\right)$ between 50 and $80 \mathrm{mmHg}$. For ventilation, we tried to achieve carbon dioxide partial pressure $\left(\mathrm{PaCO}_{2}\right)$ in the range of $45-55 \mathrm{mmHg}$ and $\mathrm{pH}>7.20$ during the first $96 \mathrm{hr}$; then, high $\mathrm{PaCO}_{2}$ levels were allowed while maintaining $\mathrm{pH}>7.20$. In order to avoid share stressinduced release of NO from vascular endothelium, ${ }^{28}$ gentle ventilation was used.

All newborns were intubated with a double-lumen endotracheal tube (inner diameter 2.7 and $3.2 \mathrm{~mm}$ in infants weighing 600-900 g and 1,000-1,500 g, respectively) if a deep resuscitation was needed in the delivery room, or when a $\mathrm{FiO}_{2}>0.30$ was required, or in the presence of moderate, severe, or progressive respiratory difficulty in spite of receiving continuous positive airway pressure (CPAP) of $6 \mathrm{~cm}$ water. All intubated infants received surfactant (Survanta, Ross Laboratories, Columbus, OH) at $4 \mathrm{ml} / \mathrm{kg}$ (100 mg of phospholipids/ $\mathrm{kg}$ ), which was repeated if needed. Initial ventilatory setting included flow 5-8 L/min, PEEP $5 \mathrm{~cm} \mathrm{H}_{2} \mathrm{O}$, RF 60 breaths/min, and $\mathrm{FiO}_{2}$ to keep $\mathrm{SaO}_{2}$ in the range of $88-93 \%$. Thereafter, PIP and RF were adjusted to reach the aforementioned $\mathrm{pH}$ and $\mathrm{PaCO}_{2}$ levels. Sedation was not routinely used during the study.

\section{NO Sampling}

The sample of gas for $\mathrm{NO}$ analysis was obtained taking into account that no exogenous surfactant was administered in the previous $6 \mathrm{hr}$ and in the presence of correct humidification of the circuit, correct calibration of the NO apparatus (chemiluminescence technique), and low proportion of $\mathrm{NO}(<40 \mathrm{ppb})$ in the compressed wall air. NO sampling was performed as previously described ${ }^{22}$ and trying to standardize the ventilation parameters ${ }^{21}$ $\left(\mathrm{FiO}_{2}=0.21, \mathrm{RF}=50\right.$ respirations $/ \mathrm{min}, \mathrm{Ti}=0.4 \mathrm{sec}$, PIP $=20 \mathrm{~cm}$ water, PEER $=5 \mathrm{~cm}$ water) during the 3 min of NO sampling. This change in the ventilation parameters was well tolerated and in only 12 cases we had to increase $\mathrm{FiO}_{2}$ to $<0.35$. The sample of gas in which NO was analyzed was obtained through a " 6 French" arterial catheter introduced into the endotracheal tube to its tip. This catheter is the narrowest that permits adequate aspiration of the gas sample without generating an alarm in the Sievers NOA apparatus. Furthermore it occupies very little of the endotracheal cross-sectional area, and hence does not affect ventilation of the lung. Three samples of gas during $1 \mathrm{~min}$ each were obtained. The mean intrasubject coefficient of variability of exhaled NO levels (in $\mathrm{ppb}$ ) was calculated from the mean of three 1-min sampling periods in each of the 54 infants. The coefficient of variation was $12.7 \%$.

\section{Influence of Air Contamination}

The absence of environmental air contamination in exhaled NO samples was confirmed by the lack of correlation between ambient $\mathrm{NO}$ and exhaled $\mathrm{NO}$ in $\mathrm{ppb}$ ( $\mathrm{n}=54, \rho=-0.35, P=0.802)$ as well as between inhaled NO and exhaled NO in ppb $(n=54$, $\rho=0.176, P=0.203$ ). The mean (standard deviation, SD) inspired NO level was 1.27 (0.91) ppb (range 0-4.1).

\section{Calculation of Plateau NO and Minute Exhaled NO}

The NO level assessed is not the highest peak, but rather the plateau value given by the software of the Sievers NOA apparatus. This plateau value is the most reliable equivalent of the NO exhaled during expiration (corresponding to the average NO detected between $1 / 2$ and $7 / 8$ of the duration of expiration). Sievers NOA 280i is able to detect from $0.5 \mathrm{ppb}$ to $500 \mathrm{ppm}$ of NO, with a sensitivity of $0.5 \mathrm{ppb}$, aspirating a gas sample of $10-200 \mathrm{ml} / \mathrm{min}$ $(100 \mathrm{ml} / \mathrm{min}$ in our study) and with a lag time of $1 \mathrm{sec}$ and an electronics response time of $0.067 \mathrm{sec}$ (sampling 
rate of $15 \mathrm{~Hz}$ ) to $90 \%$ full scale. This high speed means the apparatus can differentiate between inspired gas (contaminated with compressed air) and expired gas, which adopts the form of a plateau. Minute exhaled NO or minute excretion of NO was calculated using the formula:

$$
\begin{gathered}
\mathrm{V}^{\prime}{ }_{\mathrm{NO}}(\mathrm{nl} / \mathrm{min})=\text { Plateau } \mathrm{NO}(\mathrm{ppb}=\mathrm{nl} / \mathrm{L}) \\
\times \mathrm{V}_{\mathrm{E}}(\text { minute ventilation in } \mathrm{L} / \mathrm{min})
\end{gathered}
$$

$\mathrm{V}_{\mathrm{E}}$ has been previously corrected by the percentage of leakage given by the software of the Babylog 8000 ventilator using the formula:

$$
\mathrm{V}_{\mathrm{E}}(\mathrm{L} / \mathrm{min})=\frac{\text { Volume per minute }(\mathrm{L} / \mathrm{min})}{(100-\text { leakage }) / 100}
$$

Finally, minute exhaled NO was divided by the weight in kilograms of the newborn to obtain the minute exhaled $\mathrm{NO} / \mathrm{kg}(\mathrm{nl} / \mathrm{min} / \mathrm{kg}$ ). To convert $\mathrm{nl}$ to $\mathrm{nmol}$, it should be remembered that $1 \mathrm{~mol}=24.3 \mathrm{~L}$, when environmental temperature is $23^{\circ} \mathrm{C}$.

The results can be normalized by applying the formula developed in a previous report ${ }^{22}$ as follows: Normalized minute exhaled $\mathrm{NO}=$ minute exhaled $\mathrm{NO}$ without leakage - minute exhaled NO deviation, being minute exhaled NO deviation $=-173.668 \times($ exhaled $\mathrm{NO} / 100)^{3}+49.513 \times($ exhaled $\mathrm{NO} / 100)+12.486 \times$ $(\mathrm{VM} / 100)^{3}+24.075 \times(\mathrm{PIP} / 100)+12.371 \times(\mathrm{RF} / 100)^{3}-$ 8.126 - average minute exhaled NO.

\section{Collection of Endotracheal Aspirate Fluid Samples}

Collection of endotracheal aspirate fluid samples was performed before the administration of exogenous surfactant or at least $6 \mathrm{hr}$ later ${ }^{29}$ coinciding with routine aspirations and according to the dry technique, which for research purposes is equally valid than the bronchoalveolar lavage. ${ }^{30}$ To obtain the mucus aspirated inside the catheter, the catheter was cleaned with $1 \mathrm{ml}$ of normal saline into a tube and finally purged with air. The entire procedure was repeated to have a $2 \mathrm{ml}$ sample, $1 \mathrm{ml}$ of which was placed in another tube for nitrites-nitrates analysis. Moreover, $1 \mathrm{ml}$ of the same normal saline was placed in another tube as it may be contaminated by different amounts of nitrites-nitrates. Likewise, $0.2 \mathrm{ml}$ for analysis of IL-8 and $0.2 \mathrm{ml}$ for analysis of proteins were also kept. The diluted endotracheal aspirate fluid samples were centrifuged and the supernatant was recovered and frozen at $-80^{\circ} \mathrm{C}$, as the tube with normal saline only. Samples were delivered to the laboratory on ice.

\section{Measurement of Nitrites-Nitrates, IL-8, and Protein Levels in Endotracheal Aspirates}

The concentration of nitrites-nitrates in endotracheal aspirates was measured by a modification of the fluorimetric technique based on the reaction between 2,3-diaminonaphthalene and nitrites in acid medium. Previous filtration in Ultrafee column (UFC4 LGC, Millipore Corp., Bedford, MA) is needed to avoid interferences with serum components. The detection limit of the technique is $0.01-50 \mu \mathrm{mol} / \mathrm{L}$. Results were expressed in $\mu \mathrm{mol} / \mathrm{L}$ and in relation to the concentration of proteins. Levels of IL-8 were measured by a highly sensitive ELISA technique (Diasource Systems) and results were expressed as $\mathrm{pg} / \mathrm{ml}$ and in relation to the concentration of proteins. Proteins were measured by an automated method to normalize nitrites-nitrates and IL-8 concentrations per gram of proteins in the endotracheal aspirate fluid, so that errors related to differences in the amount of collected samples were avoided.

\section{Variables}

In all infants and before the $36 \mathrm{hr}$ of life, the following variables were recorded: gestational age, sex, birth weight, hours of life, history of maternal chorioamnionitis, maternal smoking during pregnancy, cesarean section, severity of illness (CRIB and SNAPPE-II score), concomitant diseases, such as severe RDS, air leak, patent ductus arteriosus, severe periintraventricular hemorrhage (grades 3-4), early sepsis, early exhaled NO (minute exhaled NO/ $\mathrm{kg}$ [expressed as $\mathrm{nl} / \mathrm{min} / \mathrm{kg}$ ], actual and normalized value), ${ }^{22}$ and concentrations of nitrites-nitrates ( $\mu \mathrm{mol} / \mathrm{L}$ and $\mu \mathrm{mol} / \mathrm{g}$ proteins) and IL- 8 ( $\mathrm{pg} / \mathrm{ml}$ and $\mathrm{pg} / \mathrm{g}$ proteins) in the endotracheal aspirate fluid.

\section{Statistical Analysis}

Continuous variables were presented as mean \pm SD if normally distributed and with homogeneous variances or as median and interquartile range (IQR: 25th to 75th percentiles) if not normally distributed or without homogeneous variances. These latter variables were birth weight; C-reactive protein levels; nitrites-nitrates, IL-8, and protein levels in endotracheal aspirates; duration of supplemental oxygen therapy; and all exhaled NO measurements. The influence of environmental NO or NO in compressed air on exhaled NO was analyzed by means of Spearman correlation, as well as other correlations between exhaled NO and other variables, particularly levels of nitrites-nitrates and IL-8 in endotracheal aspirates, and days of supplemental oxygen therapy. The Student's $t$-test was used for the comparison of parametric variables and the Mann-Whitney $U$-test for the comparison of non-parametric variables among the different groups according to "maternal chorioamnionitis" (yes/ no). Infants with and without history of maternal chorioamnionitis were matched by birth weight. Categorical variables were compared with the chi-square $\left(\chi^{2}\right)$ test or the Fisher's exact test. To determine the most useful cut-point of exhaled NO as a marker of history 
of chorioamnionitis, the value with the best relation sensitivity-specificity and the highest positive likelihood ratio was chosen. Statistical significance was set at $P<0.05$.

\section{RESULTS}

\section{Control Group}

As shown in Table 1, the two groups of neonates without history of maternal chorioamnionitis showed statistically significant differences in the use of antenatal steroids, gestational age, birth weight, and Apgar score at $5 \mathrm{~min}$ after birth. In addition (Table 2), there were significant differences in exhaled NO expressed as $\mathrm{nl} / \mathrm{min}$ and normalized exhaled NO expressed as either $\mathrm{nl} / \mathrm{min}$ or $\mathrm{nl} / \mathrm{min} /$ $\mathrm{kg}$. Therefore, the two subgroups were not homogeneous, and the most similar to the study group was the subgroup with $<2,000 \mathrm{~g}$ of birth weight. This subgroup will be considered the control group.

\section{Comparison of Infants With and Without History of Maternal Chorioamnionitis}

Clinical findings and morbidity according to history of maternal chorioamnionitis are shown in Table 1. Preterm newborns in the chorioamnionitis group compared with controls weighing $<2,000 \mathrm{~g}$ were less frequently born by cesarean section and mothers were older. Moreover, a significantly higher percentage of infants with history of maternal chorioamnionitis needed resuscitation and endotracheal intubation more frequently and presented with patent ductus arteriosus or severe intraventricular hemorrhage. The only newborn who died from the chorioamnionitis group was a 25 weeks' preterm infant with a

TABLE 1-Characteristics of the Study Groups With and Without Chorioamnionitis

\begin{tabular}{|c|c|c|c|c|c|}
\hline \multirow[b]{3}{*}{ Variable } & \multicolumn{3}{|c|}{ Maternal chorioamnionitis } & \multirow{3}{*}{$\begin{array}{c}P \text {-value } \\
\text { (groups } 1 \text { vs. } 2 \text { ) }\end{array}$} & \multirow{3}{*}{$\begin{array}{c}P \text {-value } \\
\text { (groups } 2 \text { vs. 3) }\end{array}$} \\
\hline & \multicolumn{2}{|c|}{ Absent } & \multirow{2}{*}{$\begin{array}{c}\text { Present } \\
\text { (group 3) }\end{array}$} & & \\
\hline & $\geq 2,000 \mathrm{~g}($ group 1$)$ & $<2,000 \mathrm{~g}($ group 2$)$ & & & \\
\hline Total infants & 13 & 26 & 15 & & \\
\hline \multicolumn{6}{|l|}{ Mother and labor } \\
\hline Age, years, mean (SD) & $32.8(3.9)$ & $30.0(3.9)$ & $33.8(4.8)$ & 0.185 & 0.039 \\
\hline Smoking during pregnancy & 0 & $6(23.0)$ & 0 & 0.158 & 0.120 \\
\hline Antibiotic treatment & $9(69.2)$ & $15(62.5)$ & $13(92.9)$ & 0.734 & 0.059 \\
\hline Antenatal steroids & $4(30.8)$ & $22(84.6)$ & $14(93.3)$ & 0.003 & 0.411 \\
\hline Inborn & $8(61.5)$ & $22(84.6)$ & $15(100)$ & 0.129 & 0.278 \\
\hline Cesarean section & $8(61.5)$ & $19(73.1)$ & $5(33.3)$ & 0.486 & 0.012 \\
\hline Multiple gestation & $3(23.1)$ & $11(42.3)$ & $7(46.7)$ & 0.409 & 0.786 \\
\hline \multicolumn{6}{|l|}{ Newborns } \\
\hline Hours of life, mean (SD) & $21.8(8.6)$ & $21.5(7.3)$ & $17.1(7.9)$ & 0.997 & 0.224 \\
\hline Male & $10(76.9)$ & $13(50)$ & $8(53.3)$ & 0.112 & 0.839 \\
\hline Gestational age, weeks, mean (SD) & $34.1(1.6)$ & $29.2(2.4)$ & $28.1(2.7)$ & 0.000 & 0.386 \\
\hline Birth weight, median (IQR) & $2,200(2,160-2,610)$ & $1,020(970-1,400)$ & $1,100(850-1,360)$ & 0.000 & 0.968 \\
\hline Intrauterine growth restriction & 0 & $3(11.5)$ & 0 & 0.524 & 0.457 \\
\hline Resuscitation (endotracheal tube) & 0 & $7(26.9)$ & $9(60)$ & 0.105 & 0.037 \\
\hline Apgar score at 5 min, mean (SD) & $9.8(0.4)$ & $8.0(1.7)$ & $8.1(1.5)$ & 0.003 & 0.959 \\
\hline CRIB score ${ }^{1}$, mean (SD) & & $2.5(2.3)$ & $2.8(1.8)$ & & 0.746 \\
\hline SNAPPE II score, mean (SD) & $11.8(9.1)$ & $21.5(13.4)$ & $23.7(15.9)$ & 0.110 & 0.885 \\
\hline \multicolumn{6}{|l|}{ Morbidity } \\
\hline Severe respiratory distress syndrome & $9(69.2)$ & $15(57.7)$ & $11(73.3)$ & 0.491 & 0.323 \\
\hline Pneumothorax & 0 & $1(3.8)$ & $2(13.3)$ & 0.999 & 0.543 \\
\hline Patent ductus arteriosus & $3(23.1)$ & $8(30.8)$ & $10(66.7)$ & 0.719 & 0.028 \\
\hline Intraventricular hemorrhage (grades 3-4) & 0 & 0 & $4(26.7)$ & & 0.013 \\
\hline Early-onset sepsis & 0 & 0 & $2(13.3)$ & & 0.128 \\
\hline Late-onset sepsis & 0 & $2(7.7)$ & $3(20)$ & 0.544 & 0.336 \\
\hline Necrotizing enterocolitis & 0 & $2(7.7)$ & $1(6.7)$ & 0.544 & 0.999 \\
\hline Supplemental oxygen, days, median (IQR) & $2(1-4)$ & $3(1-15)$ & $3(1.5-8.5)$ & 0.208 & 0.883 \\
\hline Bronchopulmonary dysplasia & 0 & $6(23.1)$ & $3(20)$ & 0.081 & 0.999 \\
\hline Retinopathy of prematurity & 0 & $4(15.4)$ & $4(26.7)$ & 0.281 & 0.434 \\
\hline Deaths & 0 & $1(3.8)$ & $1(6.7)$ & 0.999 & 0.999 \\
\hline
\end{tabular}

IQR, interquartile range (25th to 75 th percentile).

Data as absolute numbers and percentages in parenthesis unless otherwise stated.

${ }^{1}$ In infants weighing $<1,500 \mathrm{~g}$. 
TABLE 2-Inflammatory Markers in Endotracheal Aspirate Fluid and Exhaled NO in the Study Groups With and Without Chorioamnionitis

\begin{tabular}{|c|c|c|c|c|c|}
\hline \multirow[b]{3}{*}{ Variable } & \multicolumn{3}{|c|}{ Maternal chorioamnionitis } & \multirow{3}{*}{$\begin{array}{c}P \text {-value } \\
\text { (groups } 1 \text { vs. 2) }\end{array}$} & \multirow{3}{*}{$\begin{array}{c}P \text {-value } \\
\text { (groups } 2 \text { vs. } 3 \text { ) }\end{array}$} \\
\hline & \multicolumn{2}{|c|}{ Absent } & \multirow{2}{*}{$\begin{array}{l}\text { Present } \\
\text { (group 3) }\end{array}$} & & \\
\hline & $\geq 2,000 \mathrm{~g}$ (group 1$)$ & $<2,000$ g (group 2$)$ & & & \\
\hline Total infants & 13 & 26 & 15 & & \\
\hline \multicolumn{6}{|l|}{ Inflammatory markers } \\
\hline C-reactive protein $<24 \mathrm{hr}$ life, $\mathrm{mg} / \mathrm{L}$ & $0(0-0)$ & $0(0-1)$ & $1(0-10.5)$ & 0.508 & 0.035 \\
\hline C-reactive protein $<48 \mathrm{hr}$ life, $\mathrm{mg} / \mathrm{L}$ & $3(1-13)$ & $2(1-3)$ & $9(1-25.5)$ & 0.738 & 0.140 \\
\hline Nitrites-nitrates, $\mu \mathrm{mol} / \mathrm{L}$ & $2.4(0.75-4.0)$ & $1.1(0.6-2.2)$ & $3.6(1.1-5.1)$ & 0.178 & 0.035 \\
\hline IL-8, pg/ml & $477(135-5,660)$ & $497(191-1,181)$ & $1,161(241-2,485)$ & 0.627 & 0.277 \\
\hline Proteins, mg/dl & $0.25(0.08-0.46)$ & $0.21(0.11-0.39)$ & $0.29(0.19-044)$ & 0.879 & 0.192 \\
\hline Nitrites-nitrates, $\mu \mathrm{mol} / \mathrm{L} / \mathrm{g}$ proteins & $17.9(4.6-31.5)$ & $6.1(1.6-15.4)$ & $11.8(8.0-17.5)$ & 0.178 & 0.222 \\
\hline $\mathrm{IL}-8, \mathrm{pg} / \mathrm{ml} / \mathrm{g}$ protein & $2,769(1,871-25,381)$ & $3,032(351-10,964)$ & $5,918(1,116-12,148)$ & 0.259 & 0.619 \\
\hline \multicolumn{6}{|l|}{ Exhaled NO, expressed as } \\
\hline $\mathrm{ppb}$ & $1.48(0.90-1.96)$ & $1.03(0.56-1.78)$ & $1.33(1.01-2.89)$ & 0.308 & 0.056 \\
\hline $\mathrm{nl} / \mathrm{min}$ & $0.71(0.38-0.91)$ & $0.32(0.18-0.47)$ & $0.46(0.28-0.92)$ & 0.007 & Not calculated $^{1}$ \\
\hline $\mathrm{nl} / \mathrm{min} / \mathrm{kg}$ & $0.30(0.17-0.41)$ & $0.27(0.16-0.48)$ & $0.48(0.27-0.77)$ & 0.670 & 0.021 \\
\hline \multicolumn{6}{|l|}{ Normalized exhaled NO, expressed as } \\
\hline $\mathrm{nl} / \mathrm{min}$ & $1.23(0.71-1.41)$ & $1.48(1.26-1.55)$ & $1.55(1.52-1.62)$ & 0.038 & Not calculated ${ }^{1}$ \\
\hline $\mathrm{nl} / \mathrm{min} / \mathrm{kg}$ & $0.45(0.33-0.57)$ & $1.22(0.92-1.54)$ & $1.54(1.13-1.79)$ & 0.000 & Not calculated $^{1}$ \\
\hline Peak of exhaled NO, ppb & $2.24(1.69-2.50)$ & $1.72(1.07-2.41)$ & $2.14(1.62-4.29)$ & 0.159 & 0.032 \\
\hline
\end{tabular}

Data as median an interquartile range (IQR, 25th to 75 th percentile).

${ }^{1}$ Because of lack of homogeneity of the control group (i.e., statistically significant differences between groups 1 and 2).

birth weight of $810 \mathrm{~g}$ and a CRIB score of 4, who was intubated only during the first day of life after receiving two doses of surfactant. Seven days after birth he suffered from necrotizing enterocolitis with intestinal perforation and died. The only newborn who died from the control group was a 25 weeks' preterm infant with a birth weight of $740 \mathrm{~g}$ and a CRIB score of 4 , who developed a very severe BPD and died 49 days after birth.

The values of inflammatory markers and exhaled NO according to history of maternal chorioamnionitis are shown in Table 2. C-reactive protein was higher in the chorioamnionitis group. IL-8 levels, either in absolute values or divided by the protein content of the endotracheal aspirate were also higher in this group, although statistically significant differences were not reached. However, the levels of nitrites-nitrates were significantly higher than in controls $(P=0.035)$ and were positively associated with exhaled NO in $\mathrm{ppb}(\mathrm{n}=54, \rho=0.367$, $P=0.006$ ).

Minute exhaled endogenous NO, expressed in $\mathrm{nl} / \mathrm{min} /$ $\mathrm{kg}$, was significantly higher in the chorioamnionitis group. The most useful cutoff for exhaled $\mathrm{NO}$ as a marker of history of maternal chorioamnionitis was $0.285 \mathrm{nl} / \mathrm{min} /$ $\mathrm{kg}$, with a sensitivity of $73.3 \%$, specificity of $57.7 \%$, positive predictive value of $50.0 \%$, negative predictive value of $78.9 \%$, accuracy of $63.4 \%$, positive likelihood ratio of 1.733 , negative likelihood ratio of 0.462 , and area under the curve of $0.718(P=0.021)$.

Peak values of exhaled NO were significantly higher in the chorioamnionitis group than in controls $(P=0.032)$ and also showed a significant correlation with nitritesnitrates levels in the endotracheal aspirate fluid $(n=54$, $\rho=0.322, P=0.018$ ).

\section{DISCUSSION}

In the healthy newborn, exhaled NO is not affected by the gestational age, ${ }^{13,16,29,31,32}$ birth weight, ${ }^{33}$ or mode of delivery, ${ }^{29}$ although there is an increase in exhaled NO during the first week of life. ${ }^{16,29}$ Exhaled NO is not related either with serum levels of nitrites and nitrates, ${ }^{13,24}$ but there may be a relationship with nitrites and nitrates that are present in the low respiratory tract. ${ }^{33}$ In addition, there are two trends in the publications of research groups working on expired or exhaled NO in newborns: those authors who work only with concentrations $(\mathrm{ppb})^{6,12-14,16,17,34}$ and those as our group who prefer to adapt the methodologies to present the results as "total excretion of exhaled NO" $(\mathrm{nl} / \mathrm{min} / \mathrm{kg}){ }^{17,29,31,32,35,36}$ Olsen et al. ${ }^{15}$ in 2003, measured exhaled NO in eight preterm infants with RDS and showed a decline of median minute excretion of NO by $48-72 \mathrm{hr}$. Williams et al. ${ }^{16}$ measured nasal and lower airway NO level in very immature infants (median gestational age 27 weeks) and found that nasal and lower airway NO levels did not correlate significantly with gestational age, but lower airway NO levels correlated with postnatal age.

As far as we are aware, the relationship between maternal chorioamnionitis and possible increases in nitrites-nitrates levels in endotracheal aspirates and 
exhaled NO during the first days of life have not been previously investigated. In the present study, these parameters were examined exclusively in mechanically ventilated preterm infants with RDS. The increase of plateau and peak exhaled $\mathrm{NO}$ and their positive correlation with endotracheal nitrites-nitrates suggest that both factors are related and due to the same inflammatory process. It has been shown that nitrate concentration in bronchoalveolar lavage fluid is elevated in infants who developed chronic lung disease of prematurity. ${ }^{33}$ In the present study, mean IL-8 values were higher in the chorioamnionitis group than in the control group (1,161 vs. $497 \mathrm{pg} / \mathrm{ml})$, although differences were not statistically significant $(P=0.277)$, probably because of the high dispersion of values. It is likely that changes in IL-8 would have been more apparent with a larger sample size.

The birth weight cutoff point of 2,000 g was empirically chosen in an attempt to homogenize the sample in order to analyze the results of exhaled NO in different forms (including $\mathrm{ppb}, \mathrm{nl} / \mathrm{min}, \mathrm{nl} / \mathrm{min} / \mathrm{kg}$, and normalized values). It was observed that plateau exhaled NO expressed in $\mathrm{nl} /$ min was significantly different between the two control subgroups; therefore, this measurement is not useful in clinical practice. The same findings were observed for normalized plateau exhaled $\mathrm{NO}$ expressed as either $\mathrm{nl} / \mathrm{min}$ or $\mathrm{nl} / \mathrm{min} / \mathrm{kg}$. A comparison of the chorioamnionitis group with the control subgroup of $<2,000 \mathrm{~g}$ seems reasonable as both groups were homogeneous regarding gestational age and birth weight. However, if comparisons would have been performed with the 15 infants in the chorioamnionitis group and all 39 controls, heterogeneity of controls would probably account for the disappearance of statistically significant differences for nitrites-nitrates $(\mu \mathrm{mol} / \mathrm{L})$ and peak of exhaled NO (ppb) between infants in the chorioamnionitis and controls of $<2,000 \mathrm{~g}$. In fact, a positive aspect of the present study was the stratification of infants in the control group according to birth weight, which allowed comparing infants in the chorioamnionitis group with only those preterm babies without history of chorioamnionitis and similar features of immaturity and birth weight. This stratification also revealed that in controls, the expression of exhaled NO in $\mathrm{nl} / \mathrm{min}$, both in actual and normalized values was not homogeneous. When exhaled NO was expressed according to the birth weight, actual values of exhaled NO appeared homogeneous, in contrast with normalized values which are even spread out more. Therefore, the attempt to normalize exhaled NO reported in a previous study, ${ }^{22}$ unfortunately is not useful in clinical practice. In this respect, plateau of exhaled NO in $\mathrm{ppb}$ and $\mathrm{nl} / \mathrm{min} / \mathrm{kg}$ and peak of exhaled NO in ppb seem to be the only useful parameters in clinical practice. Another positive aspect was the absence of subclinical chorioamnionitis in the control group, because in that group the histology of the placenta had to be normal.
The present findings should be interpreted taking into account some limitations of the study, particularly the exclusion of perinatal sepsis; in this case, marked increases in endogenous NO with secondary increase of exhaled NO have been reported. ${ }^{37}$ In addition, the study was restricted to the first $36 \mathrm{hr}$ of life, and may be thereafter other results would be obtained.

One difficulty when attempting to analyze exhaled NO of bronchoalveolar origin is the risk that the determination could be invalidated due to NO contained in the gas inhaled. This is not the case when using the "breath program" software which accompanies the Sievers Nitric Oxide Analyzer (NOA 280i) in the mode designated "use pressure for breath detection mode," and with "online sampling." It is considered that the gas in the region between $1 / 2$ and $7 / 8$ of the duration of expiration is equivalent to the third and fourth quartiles of the expiration time, when the gas obtained is exclusively bronchoalveolar, ${ }^{38}$ with no possibility of external contamination. The manufacturers of the NOA 280i only recommend the use of medicinal air (NO-free) when environmental NO levels exceed 40-50 ppb. Our compressed air NO levels never reached these values (range $0-4.1 \mathrm{ppb}$ ). For repeated measurements of exhaled NO in each expiration, it should be available a chemiluminescence analyzer of rapid response $(\leq 0.2 \mathrm{sec})$ and at a flow rate of $>1.7 \mathrm{ml} /$ sec (Sievers NO analyzer [NOA 280] with a response time of $0.2 \mathrm{sec}$ and a minimum sample of $100-300 \mathrm{ml} / \mathrm{min}$ ).

In our previous study, ${ }^{22}$ it was shown that the variable volume per minute was highly influenced by the percentage of leakage given by the ventilator. Although the leakage of gas around the endotracheal tube is low, the sample of gas aspirated by the analyzer is considered as a leak by the ventilator. This leakage can be corrected mathematically, and indeed this should always be done. Therefore, in the present study minute exhaled NO was obtained multiplying the plateau NO value (plateau between $1 / 2$ and $7 / 8$ of expiration) by the volume per minute, as Olsen et al. ${ }^{15}$ have previously reported, but volume per minute was previously corrected by the percentage of leakage.

In the present study, exhaled NO obtained at the tracheobronchial level and during the expiratory phase was expressed as total exhaled $\mathrm{NO}$ in $\mathrm{nl} / \mathrm{min} / \mathrm{kg}$, and this value was also normalized according to setting of ventilation parameters. ${ }^{22}$ Median values of exhaled NO were 0.48 and $0.27 \mathrm{nl} / \mathrm{min} / \mathrm{kg}$ in infants with and without history of maternal chorioamnionitis, respectively. These figures are similar to those reported by Olsen et al. ${ }^{15}$ who showed that minute excretion of NO (divided by the weight) in premature infants with RDS and mechanically ventilated at $24 \mathrm{hr}$ of life was $0.405 \mathrm{nl} / \mathrm{min} / \mathrm{kg}$. In our group of chorioamnionitis, higher values of exhaled $\mathrm{NO}$ in $\mathrm{nl} /$ $\mathrm{min} / \mathrm{kg}$ were found. A value of exhaled $\mathrm{NO}>0.285 \mathrm{nl} /$ $\mathrm{min} / \mathrm{kg}$ would be suggestive of history of maternal 
chorioamnionitis with a $50 \%$ positive predictive value. This low figure and the fact that exhaled NO should be measured in the postnatal period preclude the clinical use of this parameter as a diagnostic criterion of chorioamnionitis. The increase in exhaled NO in $\mathrm{nl} / \mathrm{min} / \mathrm{kg}$ and in nitrites-nitrates levels in the endotracheal aspirate fluid, and the positive correlation between both parameters, would support the common origin of NO in the lower respiratory airway as a result of the inflammatory process.

On the other hand, a significant higher incidence of BPD in the chorioamnionitis groups was not observed, which may be explained by the use of antibiotic treatment and antenatal corticoids for fetal maturation, all of which attenuates the inflammatory process. ${ }^{39}$ Lahra et al. ${ }^{40}$ even suggested that fetal inflammatory response during chorioamnionitis is a protective factor for chronic lung disease. May et al. ${ }^{41}$ reported the peak exhaled NO values obtained on days $3,5,7,14,21$, and 28 after birth in 80 preterm infants of $<32$ weeks of gestation, depending on the appearance of BPD. In the 20 preterm infants who did not develop BPD, mean (SD) peak exhaled NO level at 3 days was 4.8 (2.5) ppb. In our study, mean peak exhaled NO level in the chorioamnionitis group was $2.14 \mathrm{ppb}$ (range 1.62-4.29), which is somewhat lower. This may be due to age differences at the time of sampling (mean $17.1 \mathrm{hr}$ in our study and 3 days in the study of May et al. ${ }^{41}$ ).

We conclude that maternal chorioamnionitis is associated with an increase of early exhaled $\mathrm{NO}(\mathrm{nl} / \mathrm{min} / \mathrm{kg})$ in mechanically ventilated preterm infants weighing $<2,000 \mathrm{~g}$. Chorioamnionitis is also associated in the newborn with an increase of C-reactive protein and of endotracheal nitrites-nitrates levels but not of early IL-8. Although an early single measurement of exhaled NO has little clinical applicability as a marker of lung inflammation, repeated measurements during the first days or weeks of life when the infant is intubated and mechanically ventilated showing increasing values may be useful to suspect BPD. May et al. ${ }^{41}$ have shown that an increase exhaled NO along the first 28 days of life was related to $\mathrm{BPD}$, and that there was a linear trend in exhaled NO results as severity of BPD increased. In these circumstances, treatment could be prescribed to improve the prognosis of this chronic lung disease.

\section{ACKNOWLEDGMENTS}

We thank Marta Pulido, MD, for editing the manuscript and editorial assistance. This study was supported by a grant from the National Health Service (FISS PI060052), Instituto Carlos III, Madrid, Spain.

\section{REFERENCES}

1. Romero R, Espinoza J, Gonçalves LF, Kusanovic JP, Friel L, Hassan S. The role of inflammation and infection in preterm birth. Semin Reprod Med 2007;25:21-39.
2. Bracci R, Buonocore G. Chorioamnionitis: a risk factor for fetal and neonatal morbidity. Biol Neonate 2003;83:85-96.

3. Newton ER. Preterm labor, preterm premature rupture of membranes, and chorioamnionitis. Clin Perinatol 2005;32:571-600.

4. Hagberg H, Wennerholm UB, Sävman K. Sequelae of chorioamnionitis. Curr Opin Infect Dis 2002;15:301-306.

5. Been JV, Zimmermann LJI. Histological chorioamnionitis and respiratory outcome in preterm infants. Arch Dis Child Fetal Neonatal Ed 2009;94:F218-F225.

6. Colnaghi M, Condo V, Pugni L, Fumagalli M, Mosca F. Endogenous nitric oxide production in the airways of preterm and term infants. Biol Neonate 2003;83:113-116.

7. Egreteau L, Pauchard JY, Semama DS, Matis J, Liska A, Romeo B, Cneude F, Hamon I, Truffert P. Chronic oxygen dependency in infants born at less than 32 weeks' gestation: incidence and risk factors. Pediatrics 2001;08:e26.

8. Redline RW, Wilson-Costello D, Hack M. Placental and other perinatal risk factors for chronic lung disease in very low birth weight infants. Pediatr Res 2002;52:713-719.

9. Van Marter LJ, Dammann O, Allred EN, Leviton A, Pagano M, Moore M, Martin C. Chorioamnionitis, mechanical ventilation, and postnatal sepsis as modulators of chronic lung disease in preterm infants. J Pediatr 2002;140:171-176.

10. Alving K, Weitzberg E, Lundberg JM. Increased amount of nitric oxide in exhaled air of asthmatics. Eur Respir J 1993;6:13681370.

11. Nelson BV, Sears S, Woods C, Ling Y, Hunt L, Clapper M, Gaston B. Expired nitric oxide as a marker for childhood asthma. J Pediatr 1997; 130:423-427.

12. Artlich A, Jonsson B, Bhiladvala M, Lonnqvist PA, Gustafsson LE. Single breath analysis of endogenous nitric oxide in the newborn. Biol Neonate 2001;79:21-26.

13. Biban P, Zangardi T, Baraldi E, Dussini N, Chiandetti L, Zacchello F. Mixed exhaled nitric oxide and plasma nitrites and nitrates in newborn infants. Life Sci 2001;68:2789-2797.

14. Aikio O, Pokela ML, Hallman M. Exhaled and nasal nitric oxide in mechanically ventilated preterm and term newborns. Acta Paediatr 2002;91:1078-1086.

15. Olsen SL, Clark PL, Thibeault DW, Norberg M, Truog WE. Exhaled nitric oxide and tracheal endothelin- 1 in preterm infants with and without RDS. Pediatr Pulmonol 2003;36:421-426.

16. Williams O, Rafferty GF, Hannam S, Milner AD, Greenough A. Nasal and lower airway levels of nitric oxide in prematurely born infants. Early Human Dev 2003;72:67-73.

17. Williams O, Bhat RY, Cheeseman P, Rafferty GF, Hannam S, Greenough A. Exhaled nitric oxide in chronically ventilated preterm infants. Arch Dis Child Fetal Neonatal Ed 2004;89:F88-F89.

18. Roiha HL, Kuehni CE, Zanolari M, Zwahlen M, Baldwin DN, Casaulta C, Nelle M, Frey U. Alterations of exhaled nitric oxide in preterm infants with chronic lung disease. Eur Respir J 2007;29: $251-258$.

19. Williams O, Dimitriou G, Hannam S, Rafferty GF, Greenough A. Lung function and exhaled nitric oxide levels in infants developing chronic lung disease. Pediatr Pulmonol 2007;42:107-113.

20. ATS/ERS. Recommendations for standardized procedures for the online and offline measurement of exhaled lower respiratory nitric oxide and nasal nitric oxide. Am J Resp Crit Care Med 2005;171: 912-930.

21. Williams O, Greenough A, Wong ML, Hannam S, Rafferty GF, Milner AD. Influence of ventilatory settings and sampling position on measurements of simulated exhaled nitric oxide levels. Physiol Meas 2003;24:1-9.

22. Figueras-Aloy J, Berrueco R, Salvia-Roiges MD, RodriguezMiguélez JM, Miracle-Echegoyen X, Botet-Mussons F, MurSierra A, Vall O, Carbonell-Estrany X. Attempt to normalize 
simulated exhaled nitric oxide according to ventilatory settings. Pediatr Pulmonol 2008;43:1167-1174.

23. Harrison CM, Andersen CC. Exhaled breath measures of inflammation: are they useful in neonatal chronic lung disease? Arch Dis Child Fetal Neonatal Ed 2005;90:6-10.

24. De Dooy J, Colpaert C, Schuerwegh A, Bridts C, Van Der Planken M, Ieven M, De Clerck L, Stevens W, Mahieu L. Relationship between histologic chorioamnionitis and early inflammatory variables in blood, tracheal aspirates, and endotracheal colonization in preterm infants. Pediatr Res 2003;54:113-119.

25. Jonsson B, Tullus K, Brauner A, Lu Y, Noack G. Early increase of TNF-alfa and IL-6 in tracheobronchial aspirate fluid: indicator of subsequent chronic lung disease in preterm infants. Arch Dis Child 1997;77:F198-F201.

26. Beresford MW, Shaw NJ. Detectable IL-8 and IL-10 in bronchoalveolar lavage fluid from preterm infants ventilated for respiratory distress syndrome. Pediatr Res 2002;52:973-978.

27. Jobe AH, Bancalari E. Bronchopulmonary dysplasia. Am J Respir Crit Care Med 2001;163:1723-1729.

28. Buga GM, Gold ME, Fukuto JM, Ignarro LJ. Shear stress-induced release of nitric oxide from endothelial cells grown on beads. Hypertension 1991;17:187-193.

29. Figueras-Aloy J, Jordán Y, Rodríguez-Miguélez JM, Jiménez W, Botet F, Carbonell X, Jiménez R. Expired nitric oxide in the newborn with high risk of perinatal infection. Am J Perinatol 2003;20:137-145.

30. Darlow BA, Sluis KB, Inder TE, Winterbourn CC. Endotracheal suctioning of the neonate: comparison of two methods as a source of mucus material for research. Pediatr Pulmonol 1997;23:217221.

31. Schedin U, Norman M, Gustafsson LE, Jonsson B, Frostell C. Endogenous nitric oxide in the upper airways of premature and term infants. Acta Paediatr 1997;86:1229-1235.
32. Artlich A, Busch T, Lewandowski K, Schaible T, Falke KJ, Gortner L. Expired nitric oxide in preterm infants. Respir Physiol 1998;114:195-200.

33. Vyas JR, Currie AE, Skuker DEG, Field DJ, Kotecha S. Concentration of nitric oxide products in bronchoalveolar fluid obtained from infants who develop chronic lung disease of prematurity. Arch Dis Child 1999;81:F217-F220.

34. Leipala JA, Williams O, Sreekumar S, Cheeseman P, Rafferty GF, Hannam S, Milner A, Greenough A. Exhaled nitric oxide levels in infants with chronic lung disease. Eur J Pediatr 2004;163:555558.

35. Schedin U, Norman M, Gustafsson LE, Herin P, Frostell C. Endogenous nitric oxide in the upper airways of healthy newborn infants. Pediatr Res 1996;40:148-151.

36. Figueras J, Rodríguez-Miguélez JM, Botet F, Moreno J, Jiménez R. A different methodology for evaluating the exhaled endogenous nitric oxide in the newborn. Acta Paediatr 1999;88:471-472.

37. Shi Y, Li HQ, Schen CK, Wang JH, Qin SW, Liu R, Pan J. Plasma nitric oxide levels in newborn infant with sepsis. J Pediatr 1993; 123:435-438.

38. Hall GL, Reinmann B, Wildhaber JH, Frey U. Tidal exhaled nitric oxide in healthy, unsedated newborn infants with prenatal tobacco exposure. J Appl Physiol 2002;92:59-66.

39. Botet F, Figueras J, Carbonell X, Arca G. Effect of maternal clinical chorioamnionitis on neonatal morbidity in very-low birthweight infants: a case-control study. J Perinat Med 2010;38:267-273.

40. Lahra MM, Beeby PJ, Jeffery HE. Intrauterine inflammation, neonatal sepsis, and chronic lung disease: a 13-year Hospital Cohort Study. Pediatrics 2009;123:1314-1319.

41. May C, Williams O, Milner AD, Peacock J, Rafferty GF, Hannam S, Greenough A. Relation of exhaled nitric oxide levels to development of bronchopulmonary dysplasia. Arch Dis Child Fetal Neonatal Ed 2009;94:F205-F209. 